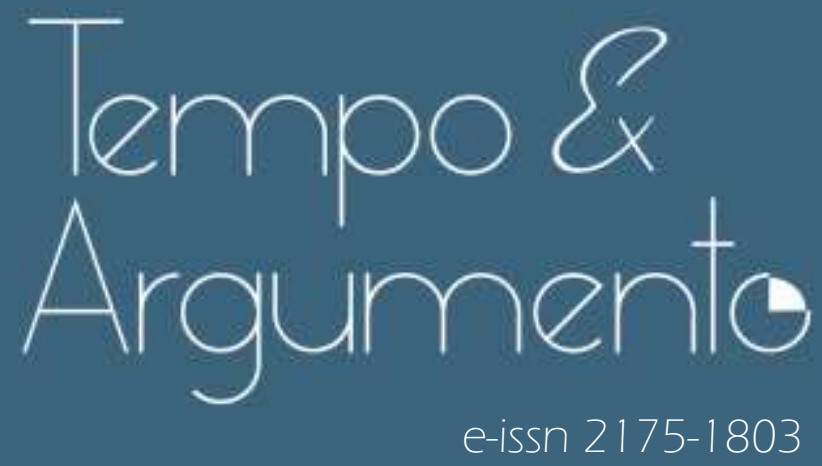

\title{
Igreja missionária, Igreja colonial: o ponto de vista dos Combonianos da Nigrizia ao longo da transição em Moçambique ( 1970-1975)
}

* Laura António Nhaueleque

Doutora em Relações Interculturais pela Universidade Aberta de Lisboa.

Investigadora da Universidade Aberta de Lisboa (Portugal) e do Instituto

Superior Monitor (Moçambique).

Lisboa - PORTUGAL

cemri.uab.pt/investigador/laura-antonio-nhaueleque/

lauramacua@gmail.com

(D) orcid.org/0000-0002-2123-0636

Para citar este artigo:

NHAUELEQUE, Laura António. Igreja missionária, Igreja colonial: o ponto de vista dos Combonianos da Nigrizia ao longo da transição em Moçambique (1970-1975).

Tempo e Argumento, Florianópolis, v. 13, n. 34, e0 108 , set./dez. 2021.

do http://dx.doi.org/10.5965/2175180313342021e0108

Recebido: 30/05/2021

Aprovado: 02/06/2021 
Igreja missionária, Igreja colonial: o ponto de vista dos Combonianos da Nigrizia ao longo da transição em Moçambique (1970-1975)

\begin{abstract}
Resumo
Esta pesquisa pretende apresentar o posicionamento dos Combonianos italianos diante das lutas independentistas nos PALOP, com destaque maior para Moçambique. Os Combonianos têm uma presença antiga e significativa em África e em Moçambique onde, principalmente no Centro e no Norte, sempre acompanharam a sua ação missionária com uma considerável proximidade às populações locais. No período que antecede a independência de Moçambique, os Combonianos lideraram o movimento de missionários e outras figuras de relevo da Igreja local para que se afirmasse uma mudança radical no tipo de missionação, assim como na lgreja no seu todo, quebrando a tradicional neutralidade dos católicos em relação ao Governo português e suas políticas. O artigo usa uma abordagem qualitativa, e está focado na análise do Jornal, Nigrizia dos Combonianos italianos, entre 1971 e 1975, procurando compreender o seu posicionamento em relação à "questão colonial", que acaba incluindo não apenas duras críticas ao colonialismo lusitano, mas também à Igreja portuguesa e moçambicana, e, em parte, às hierarquias vaticanas. Tal ponto de vista fez com que os Combonianos "apostassem" no novo Governo da FRELIMO, sem, porém, calcular os riscos e as intolerâncias para com a religião católica que o novo socialismo moçambicano protagonizou.
\end{abstract}

Palavras-chave: independência; catolicismo progressista português; violência Colonial; Nova Missionação.

\title{
Missionary Church, Colonial Church: the point of view of the Combonians of Nigrizia during the transition in Mozambique (1970-1975)
}

\begin{abstract}
This research aims to present the approach of the Italian Combonians in relation to the struggles for independence in the PALOP, with a particular emphasis for Mozambique. The Combonians have an old and significative presence in Africa and in Mozambique too, where, especially in the Centre and in the North, always accompanied their missionary action with a considerable proximity to local populations. In the period leading up to the obtaining of Mozambican independence, the Combonians leaded a movement of missionaries and other important figures inside local Catholic Church in order to favorite a radical change in the form of mission, as well as in the Church as a whole, breaking the traditional neutrality of the Catholics towards the Portuguese government and its policies. This article used a qualitative methodology, being focused on the analysis of the journal of the Italian Combonians Nigrizia between 1971 and 1975, and trying to understand their positioning in relation to the "colonial question". It includes not only harsh criticisms towards Portuguese colonialism, but also towards the Portuguese and Mozambican Church, and in part also towards the Vatican hierarchies. This perspective made the Combonians "bet" in the new government leaded by FRELIMO, but without calculating the risks and the intolerances that the new Mozambican socialism perpetrated against the Catholic religion.
\end{abstract}

Keywords: independence; Portuguese progressive catholicism; colonial violence; new mission. 


\section{Introdução}

Os países africanos de língua portuguesa (PALOP) foram os últimos, cronologicamente, a conseguir as suas independências políticas. Com efeito, se França e Reino Unido, os dois maiores países colonialistas, a que se associaram outros de menor tradição, tais como Bélgica, Itália e Espanha, resolveram descolonizar seus territórios africanos sem derramamento de sangue (com poucas exceções, concentradas na África do Norte), Portugal conseguiu resistir à onda anticolonialista até os meados da década de 1970, depois da Revolução dos Cravos de 25 de abril de 1975, que derrubou o regime de Marcelo Caetano, com consequente abertura para a democracia (MARTINHO, 2017; SECCO, 2013).

A guerra nos territórios africanos lusófonos - nomeadamente GuinéBissau, Angola e Moçambique - teve um papel relevante na queda do regime português, quer por motivos internos, quer devido à pressão exercida por parte da comunidade internacional contra um colonialismo que já há muito tempo tinha assumido contorno de acentuado anacronismo.

No entanto, a comunidade internacional, estava dividida. Por um lado, todos os países e as forças políticas incluindo ocidentais, ligadas ao bloco soviético tinham um posicionamento de dura condenação/reprovação a Portugal e ao seu colonialismo, procurando ajudar os movimentos de libertação em luta nos territórios africanos lusófonos. Por outro, os países do bloco atlântico, pelo menos alguns, a partir dos Estados Unidos, tiveram um posicionamento oscilante diante da questão colonial portuguesa. Se o pano de fundo, corroborado inclusivamente por alguns pronunciamentos das Nações Unidas, era de distanciamento do colonialismo de Lisboa, Portugal representava, porém, um aliado importante quer para o controlo do Atlântico (com as bases americanas das Lajes, nos Açores), quer para a política de contenção da influência soviética em África (SCHNEIDMAN, 2005).

A Igreja Católica, que representa o foco deste estudo, replicava, embora em formas originais, o embaraço de potências políticas como os Estados Unidos. A perspectiva do Vaticano para com o colonialismo era, no geral, clara: principalmente com João XXIII e Paulo VI, os dois Papas do Concílio Vaticano II, o

\footnotetext{
* Nesse texto optou-se por manter a grafia da língua nativa.
} 
colonialismo deixou de ser apresentado como meio de evangelização dos nãocristãos em terras de missionação, tomando o semblante de uma forma de governação que devia ser ultrapassada.

Na sua encíclica Populorum Progressio, por exemplo, papa Paulo VI abordava o colonialismo como uma época que trouxe mais prejuízos de que benefícios (que entretanto não faltaram), mas em que transparece de forma evidente que se trata de uma experiência histórica do passado, sem nenhuma possibilidade de retorno, uma vez que os povos devem pautar por um desenvolvimento autónomo e sustentável (DE JONG, 2015; HEIDT, 2017; PAOLO VI, 1967).

O caso de Portugal punha questões que o próprio Papa julgava pertencentes ao passado, como demonstra seu encontro, em 1970, com os três expoentes principais das lutas de libertação em Angola, Guiné-Bissau e Moçambique, de que se dirá mais à frente. Foi evidente, com base nesta reunião, que Paulo VI já estava olhando para os territórios na altura ainda sob o colonialismo português como terrenos de novas atividades da Igreja Católica.

Entretanto, o Vaticano nunca rompeu com Portugal, com que tinha assinado vantajosos acordos, tais como a Concordata e o Acordo Missionário, que garantiram por muito tempo ao catolicismo uma posição de primazia naqueles territórios africanos. Isso, porém, fez com que a Igreja Católica portuguesa mantivesse posições conservadoras, quase que identificando-se com - Estado e, portanto, pagando a caro preço esta sua postura aquando da obtenção da independência dos PALOP.

Esta pesquisa tenciona analisar como é que se deram tais relacionamentos entre uma Igreja de Roma com um posicionamento claro em relação à questão geral do colonialismo, mas sem querer ferir a suscetibilidade portuguesa, uma Igreja nacional em constante dificuldade em se adequar aos novos tempos que se estavam aproximando rapidamente, os católicos progressistas de Portugal e sobretudo os missionários naquelas terras africanas ainda sob o jugo colonial lusitano, que tentaram desempenhar um papel de vanguarda do catolicismo internacional, conseguindo só em parte cumprir com esta tarefa. 
Para compreender o papel dos missionários nos territórios ainda controlados por Portugal se escolheu, do ponto de vista metodológico, uma abordagem histórica, concentrada no período correspondente à governação de Caetano como Primeiro-ministro (1968-1974), e ainda mais nos primeiros cinco anos da década de 1970, os mais críticos no que diz respeito à questão colonial.

A abordagem histórica foi complementada por uma outra, centrada na análise do discurso dos Combonianos italianos, através da leitura da sua revista mensal, Nigrizia. Tal leitura foi possível graças à disponibilização, por parte da atual redação desta revista, dos artigos necessários para levar a cabo a supramencionada análise, pois sem esta preciosa ajuda esta pesquisa não teria podido ser realizada.

\section{A Igreja Católica e a questão colonial portuguesa}

A aliança entre Estado português e Igreja Católica afunda as suas raízes na própria edificação do Estado Novo por parte de Salazar. Entretanto, é possível identificar, dentro dos últimos anos deste tipo de governação, depois da morte do seu mentor e a subida no poder de Marcelo Caetano, pelo menos dois períodos relativamente distintos, caraterizados por uma cada vez maior distância entre estas duas entidades, até chegar a um verdadeiro conflito.

O primeiro destes dois períodos vai aproximadamente de 1968 (nomeação de Caetano como Presidente do Conselho dos Ministros) até 1972, e o segundo abrange os anos entre 1972 até 1974, caraterizado por massacres de civis nas colónias africanas por parte dos portugueses, expulsões de eclesiásticos e missionários e enormes dificuldades das Igrejas locais diante dos movimentos revolucionários independentistas.

\subsection{O início das desavenças (1968-1972)}

As hierarquias católicas já tinham abordado a questão colonial em várias circunstâncias, com um posicionamento que, com o pontificado de João XXIII (1958-1963), e depois de Paulo VI (1963-1978) se tornaram cada vez mais explícitas. A simpatia para com os movimentos africanos anticolonialistas se 
tinha transformado em verdadeiro elemento da doutrina social da Igreja, fundamentada na sede de justiça que o Concilio Vaticano II acentuou, favorecendo posicionamentos progressistas que durante muito tempo tinham ficado nas margens do catolicismo europeu.

Tais ideias de renovação espiritual da Igreja Católica colidiram com os interesses portugueses, principalmente na altura do regime de Marcelo Caetano (1968-1974), último Presidente do Conselho dos Ministros de Portugal do Estado Novo inaugurado em 1933 por Salazar. Moderado por natureza, Caetano teve de fazer as contas com os anacronismos de um Estado que queria continuar a exercer um poder colonial, contra qualquer tipo de lógica política e ética daquela altura, em territórios que, desde o início da década de 1960, enveredaram por um caminho de resistência armada que irá levá-los às independências, por volta dos meados da década de 1970.

Quando Marcelo Caetano ascendeu ao poder, em setembro de 1968, o catolicismo já tinha feito passos significativos no sentido de deixar posicionamentos favoráveis ao colonialismo lusitano como meio para evangelizar o continente africano, mas tendo uma Igreja portuguesa ainda enraizada nos acordos que, na década de 1940, tinham sido assinados com o Estado português.

A longa fase do "casamento" Estado-Igreja, em Portugal iniciou a ter as suas primeiras bases em 1933, ano em que Salazar lançou o Estado Novo, e em que a Igreja Católica fundou a Acção Católica Portuguesa, que já pressupunha uma unidade de ação entre instituição estadual e instituição religiosa (ESTÊVÃO, 2000). Entretanto, foi ao longo dos anos 1940 que o relacionamento entre essas duas entidades se tornou mais estável e sólido: em 1940 foram assinados a Concordata e o Acordo Missionário, e em 1941 foi aprovado o Estatuto Missionário.

Nos dois acordos acima, o Estado português garantia à Igreja Católica de ser a única legitimada para evangelizar os africanos das suas colónias, deixando a ela o monopólio da educação dos indígenas, ao passo que a Igreja concordou em combinar os nomes dos bispos a serem enviados nos territórios ultramarinos com o Governo de Lisboa, evitando, assim, a africanização da Igreja Católica naquelas terras. O pessoal religioso nas colónias portuguesas em África era quase que inteiramente proveniente da Igreja nacional, tão que foi evidente, durante 
muito tempo, um "inegável espírito patriótico dos bispos portugueses" (SALVINI, 1975, p. 184). Ainda em 1961 a hierarquia católica portuguesa sublinhava que "Portugal é consciente da sua missão evangelizadora e civilizadora" (ESTÊVÃO, 2000, p. 230).

Esta caraterização "nacionalista" do pessoal religioso enviado em terras africanas deu, por um lado, uma configuração típica à Igreja católica em Portugal e nas colónias lusófonas, e por outro iniciou a marcar uma distância cada vez mais significativa com o posicionamento da Igreja de Roma. Com efeito, o Vaticano tinha iniciado a sua viragem anticolonialista com o pontificado de João XXIII. Já em 1960 o Papa, mediante uma rádio-mensagem, expressava a sua satisfação para o acesso dos povos oprimidos às suas soberanias. E em 1963 publicou a encíclica Pacem in Terris, com explícita condenação da experiência colonial europeia e a contrariedade de qualquer forma de domínio do homem sobre o homem, inclusivamente se se tratar de sujeitos pertencentes a civilizações diferentes. Na encíclica, o Papa insere, dentro dos três elementos típicos dos "sinais do tempo", além da ascensão da classe dos trabalhadores e do ingresso da mulher na vida pública, "um padrão social e político completamente novo", ou seja, o fim da distinção entre povos dominados e dominadores (JOÃO XXIII, 1963).

No ano seguinte o Papa Paulo VI, em continuidade com o pontificado de João XXIII, "desafiou" Portugal de forma mais direta: ele presenciou a um encontro em Bombaim (Índia), em pleno conflito entre a União Indiana e Portugal sobre Goa e os outros territórios lusófonos daquela península, deixando entender que a questão da independência para os territórios africanos era já um dado adquirido, que apenas precisava de tempo para se consumir.

O auge do conflito com Portugal se deu - nesta primeira fase do GovernoCaetano - a 1 de julho de 1970, aquando do famoso encontro de Paulo VI com os três líderes do PAIGC (Partido Africano para a Independência da Guiné e CaboVerde), FRELIMO (Frente de Libertação de Moçambique) e MPLA (Movimento Popular de Libertação da Angola), respetivamente Amílcar Cabral, Marcelino dos Santos e Agostinho Neto, considerados por Portugal como movimentos de terroristas. A justificativa do Papa foi de que "a Igreja está do lado dos países que 
sofrem", coisa que Marcelo Caetano não interpretou favoravelmente, mandando uma nota de protesto que o embaixador lusitano entregou junto à Santa Sé. Em jeito de resposta, o Vaticano procurou abafar a questão, reduzindo o encontro a um fato de nenhuma importância na agenda pontifícia. Graças a este posicionamento diplomático, as relações entre as duas entidades foram retomadas com a usual cordialidade, segundo uma expressão do primeiroministro português, fechando assim o incidente.

Este momento, todavia, sinaliza um primeiro conflito Estado-Igreja, que será destinado a se agravar nos anos seguintes, em particular desde 1972 até o fim do Estado Novo, com a deposição de Caetano, a revolução dos cravos e o Governo liderado pelo General Spínola.

Apesar dos evidentes sinais internacionais, Caetano não recuou da política colonial salazarista, forte do fato de os partidos conservadores terem ganho as eleições nos Estados Unidos e no Reino Unido, respetivamente em 1969 e 1970, e sobretudo de Washington ter renovado o acordo com Lisboa sobre a base militar nos Açores (dezembro de 1971), mas com resultados concretos abaixo das expetativas, do lado português (ANTUNES, 1992).

Em resposta a um quadro político aparentemente favorável, em 1970 Portugal ameaçou invadir a Guiné-Conacri para derrubar o "comunista" Amed Sekou Touré, numa enésima tentativa malsucedida e que não recebeu nenhuma solidariedade por parte dos aliados atlânticos. E em 1972, o ano que idealmente fecha o primeiro período de governação de Caetano sobre a questão colonial, uma reunião do Conselho de Segurança da ONU em Addis-Abeba recebeu os três líderes de PAIGC, FRELIMO e MPLA, votando inclusive uma resolução em favor das suas lutas independentistas.

Tal processo encontra a sua conclusão em novembro de 1972, quando a Assembleia Geral da ONU reconheceu os três movimentos em luta pelas independências das colónias portuguesas como "representantes autênticos" dos seus povos (OLIVEIRA, 2001). Por isso o reconhecimento da independência da Guiné-Bissau proclamada pelo PAIGC em 1973 por parte de 40 países, entre os quais muitos aliados de Portugal, representou a consequência natural do isolamento lusitano. 
No próprio território português, entre 1968 e 1972, uma parte do meio católico iniciou a assumir posicionamentos críticos diante da guerra colonial, entrando em choque, direta ou indiretamente, com o conservadorismo da Igreja nacional, em contradição com a Igreja de Roma.

As eleições portuguesas de 1969, que confirmaram Marcelo Caetano no poder, pela primeira vez introduziram no debate político oficial a questão colonial, que, portanto, já não constituía um dogma indiscutível (BARROSO, 2018). Entretanto, as aberturas do Primeiro-ministro português eram muito mais teóricas do que práticas, inclusivamente devido à pressão que as classes mais conservadoras e até reacionárias que o apoiavam exerciam, não admitindo a mínima incerteza sobre as colónias africanas.

A questão colonial se desenrolou, entre 1969 e 1972, segundo um plano duplo: por um lado, externamente, a projeção da imagem de Portugal como linha de frente europeu em África, garantindo assim a estabilidade geral da área; por outro lado, internamente, mediante una série de reformas, que visavam fortalecer o poder de Caetano, entre tímidas aberturas de matriz liberal e perseguição dos inimigos políticos, entre os quais significativos grupos de católicos progressistas.

A respeito do primeiro ponto, a duplicidade do Governo de Lisboa era expressa por meio do posicionamento do ministro dos negócios estrangeiros, Rui Patrício, que tencionava transmitir a ideia de uma "África pacífica e progressiva", cujo maior sucesso diplomático se resumiu no Manifesto de Lusaka.

Em 1969, alguns estados africanos reconheceram a diferença entre o regime colonial português, isento de racismo e discriminação, e o do apartheid da África do Sul e da Rodésia do Sul, tão que o Manifesto foi aprovado, em outubro do mesmo ano, pela Assembleia das Nações Unidas (OLIVEIRA, 2001). Ao mesmo tempo, porém, a aliança com os dois países abertamente racistas se fez cada vez mais significativa, até chegar, sob a insistência da África do Sul, à operação ALCORA, que consistia em constituir um exército comum entre Pretória, Lisboa e Salisbury, com o objetivo de controlar e dominar os conflitos em Angola e Moçambique. O Primeiro-ministro sul-africano, Vorster, condicionou a ajuda em dinheiro e armas a Portugal com o fato de o exército de Pretória 
comandar as operações junto às fronteiras dos territórios vizinhos de Angola e Moçambique.

A duplicidade do Governo-Caetano sobre a questão colonial encontrou uma enésima confirmação com relação à tentativa de Jorge Jardim de conseguir uma independência "controlada" de Moçambique, evitando o que a direita portuguesa considerava como sendo o mal pior: a hegemonia dos comunistas num Moçambique independente.

O plano de Jardim - que o mesmo explicou com muitos pormenores num livro que já ganhou muita fama (JARDIM, 1976) - visava entregar o poder a uma minoria branca, com uma participação simbólica de moçambicanos pretos no futuro Governo, mas uma clara tendência política filo-ocidental e anti-soviética. Jardim já tinha estabelecido acordos neste sentido com Banda, presidente do Malawi, e em parte com Kaunda, Presidente da Zâmbia, ao passo que o próprio Senghor, Presidente do Senegal e um dos pais do pan-africanismo, estava apelando para que houvesse um diálogo com Portugal (OLIVEIRA, 2001).

O plano de Jardim, homem forte de Salazar em Moçambique, foi recebido com muita frieza por Caetano, e nunca chegou a ser realizado, continuando assim o Governo de Lisboa a perseguir uma perspectiva indefinida em volta das suas colónias africanas, cuja única saída era a guerra.

Caetano encontrou a síntese política na fórmula que consistia em conservar a Ultramar, embora com adaptações. Tal posicionamento se traduziu na aprovação da Lei 3/71, em que Portugal se mantinha como país unitário, mas reconhecendo um estatuto próprio às regiões autónomas, representadas pelos territórios ultramarinos (CABREIRA, 2018).

Em relação à questão católica, diretamente ligada à questão colonial, Caetano cumpriu passos significativos. A Igreja Católica portuguesa devia continuar a apoiar a política africana do Governo, assim algumas concessões se tornaram necessárias: acima de tudo, foi decretado o fim do exílio do bispo do Porto em junho de 1969; a seguir, a palavra "Deus" foi introduzida, pela primeira vez, na Constituição, e a Universidade Católica portuguesa finalmente oficializada (ALMEIDA, 2004). O primeiro bispo negro foi ordenado em Angola: se tratava de 
Dom André Muaca, ordenado primeiro bispo vigário em Luanda, depois bispo em Malanje.

As medidas acima descritas serviam para abafar o descontentamento da parte mais progressista do catolicismo português, que ainda representava um elemento fundamental na edificação do colonialismo lusitano em África. Entretanto, as ambiguidades que o Governo-Caetano mostrava em relação à questão colonial se replicaram, talvez com ainda maior evidência, acerca da questão católica.

Com efeito, paralelamente às medidas de sabor cosmético acima recordadas, o Governo iniciou uma obra muito séria de perseguição dos expoentes e dos movimentos de ponta do catolicismo progressista, abrindo uma verdadeira crise no seio da Igreja entre as hierarquias, largamente fiéis a uma linha pró-governamental, e grupos de base com uma visão mais democrática, inspirada aos princípios do Vaticano II.

O pano de fundo é representado, aqui, pela ideia de uma intervenção social mais ativa da Igreja Católica na sociedade portuguesa, incluindo nesta ação a questão colonial, partindo do pressuposto de uma cidadania mais difusa, democrática e consciente (ESTÊVÃO, 2000).

Nesta ótica, as Igrejas locais, sobretudo de Moçambique e Angola, estavam completamente alinhadas ao posicionamento conservador da Igreja da madre pátria. Pronunciamentos neste sentido foram feitos quer pelos bispos de Angola, com uma Exortação Pastoral de 1961, em que a Igreja esclareceu estar fora de qualquer acontecimento político, quer pelo arcebispo de Lourenço Marques, dom Teodósio Clemente Gouveia, que identificava como inimigos irredutíveis a "mística tribal, o nacionalismo marxista, o muçulmanismo e o protestantismo" (ESTÊVÃO, 2000, p. 230). A guerra de libertação, portanto, era vista pelas hierarquias católicas moçambicanas - assim como angolanas e portuguesas como uma afronta, que devia ser evitada e contrastada com todas as forças.

Diante da contradição entre o conservadorismo católico português e a renovação que culminou com o vaticano II, os católicos progressistas portugueses iniciaram a desenvolver atividades concretas, em aberta polémica 
com as suas hierarquias nacionais: em outubro de 1965, por exemplo, saiu o Manifesto de 101 católicos contra a guerra colonial; polémica que se torna fratura insanável quando as hierarquias portuguesas expressam a opinião de que o Papa pode estar enganado acerca do posicionamento a assumir em relação ao conflito colonial (ver visita de 1970 dos três líderes dos movimentos de libertação), condenando o "terrorismo comunista" sem possibilidade de apelo (ESTÊVÃO, 2000).

Foi em Lisboa e, em parte, no Porto que se concentrou a maior oposição aberta contra o colonialismo português, criando fissuras muito significativas dentro da própria Igreja. Na capela do Rato se formou um grupo de católicos progressistas que, juntamente com 45 padres, em 29 de setembro de 1969, deu origem ao CIDAC (Clero em Diálogo e Ação) e à Tribuna Livre, uma série de reuniões dos padres de Lisboa, ao passo que os Cadernos GEDOC (Grupo de Estudo e Intercâmbio de Documentos, Informações e Experiências), liderado pelo padre Alves, foi desautorizado pelo Cardeal patriarca Cerejeira. O mesmo Cardeal suspendeu a divinis o padre Felicidade Alves de Belém, devido às suas críticas ao Governo colonial e ao seu ativismo na organização de grupos de católicos com posicionamento progressista e de publicações do mesmo teor (ALMEIDA, 2004).

Maria Conceição Mota, uma das católicas progressistas que se opunha ao regime de Caetano e à guerra colonial, recorda, numa entrevista, quão importante fosse a contribuição das publicações desse grupo de católicos. Os Cadernos GEDOC, por exemplo, para fugir à censura publicavam cada número com um nome bíblico. A partir daí, e graças à obra do padre Alves, iniciou-se a publicar um Boletim Anti-Colonial, que também caiu nas malhas da polícia política portuguesa (PR, 2014). Outras publicações como "O Tempo e o Modo" e o "Direito à Informação" também desempenharam um papel fundamental na consciencialização dos católicos portugueses contra a guerra colonial e em favor de uma mudança radical do regime político.

O auge das confrontações entre Governo português e grupo dos católicos progressistas se deu, numa primeira fase, na ocupação da Igreja de S. Domingos entre 31 de dezembro de 1968 e 1 de janeiro de 1969. Cerca de 150 católicos 
permaneceram toda a noite naquela Igreja, depois de Paulo VI ter estabelecido que 1 de janeiro passaria a ser o Dia Mundial da Paz.

Aquela vigília dos católicos terminou sem incidentes, embora com a constante presença da PIDE que, inclusive, teve de ouvir a Cantata da Paz, escrita por Sophia de Mello Breyner, cujos primeiros versos ela própria recorda, numa entrevista: "Vemos, ouvimos e lemos/Não podemos ignorar" (MARTINS, 2014). Foram esses versos que resumiram o compromisso dos católicos progressistas, a partir dos quais a oposição ao Governo-Caetano, à guerra colonial e em prol da paz vieram-se fortalecendo nos anos seguintes, até a queda de 25 de abril.

\subsection{A rutura do catolicismo progressista com as hierarquias eclesiásticas nacionais em volta da questão colonial (1972-1974)}

Os últimos dois anos do Governo-Caetano e do colonialismo português foram os mais conturbados, quer dentro do mundo colonial lusitano, quer no seio do espaço político e religioso da madre pátria.

As questões, aqui, se concentram na última fase do colonialismo e da guerra que o Governo português estava levando a cabo contra os movimentos de libertação, com cada vez mais mortos e até massacres consumidos contra as populações civis indefesas. Se, em Angola, missionários como Adalberto da Postioma foram expulsos definitivamente do país, em rotura com a hierarquia católica oficial, foi provavelmente em Moçambique onde se deu a rotura mais evidente no seio do catolicismo (NHAUELQUE; BUSSOTTI, 2019).

Em Moçambique, em novembro de 1971, por exemplo, o exército colonial tinha protagonizado uma chacina em Mucumbura, na província de Tete, que devia ficar escondida junto à opinião pública. Entretanto, dois padres da Igreja de Macuti, na cidade da Beira, Joaquim Teles Sampião e Fernando Marques Mendes, deram a conhecer o fato aos fiéis, acrescentando informações sobre práticas difusas de tortura por parte das autoridades coloniais, provavelmente sob as ordens de Jorge Jardim (BRANDÃO, 2004), perguntando por que, em Moçambique, devia haver guerra e não paz (MORAIS, 2020). Juntamente com o aprisionamento dos padres Sampião e Mendes, os Padres de Burgos foram expulsos, no início de 1972, e muitos catequistas tiveram de se juntar ao exército 
português na luta anticolonial, e outros foram presos pela polícia política (BRANDÃO, 2004).

Pouco tempo depois (dezembro de 1972), ainda na província de Tete, desta vez em Wiryiamu, outro massacre foi protagonizado por parte da tropa portuguesa. O episódio foi conhecido pela opinião pública internacional somente em julho de 1973, quando Adrian Hastings, um antigo padre missionário em terra africana, relatou o acontecimento em "The London Times", aquando da visita em Londres de Marcelo Caetano (DHADA, 2016).

Nos derradeiros anos da luta de libertação, depois de o General Kaúlza de Arriaga ter desencadeado a Operação Nó Górdio em Cabo Delgado, a frente mais forte/resistente da luta se concentrou em Tete. Aqui, um avião português de pequeno porte foi atingido, mas sem nenhuma consequência negativa do lado dos tripulantes. Apesar disso, uma expedição foi enviada para averiguações no local, mas esta caiu numa emboscada da FRELIMO. Humilhados, como forma de retaliação e punição, a vingança dos portugueses se concentrou nas aldeias de Wuryiamu, Chawola e Jumau.

Em Tete, o bairro de Wuryiamu foi bombardeado e, a seguir, ocupado por parte dos Grupos Especiais de Paraquedistas, que fuzilaram homens, mulheres e crianças. Muitas crianças morreram pontapeadas pelos soldados, a seguir, iniciaram um macabro jogo de futebol, onde a bola eram os corpos das crianças (HASTINGS, 1974).

Em paralelo, na Igreja de Portugal, a oposição dos católicos progressistas se reforçou, devido ao conhecimento de tais episódios. Por volta de 1972 vários católicos democráticos escreveram um texto sobre o fracasso do reformismo governamental, juntamente com socialistas e comunistas, com uma difusão de 10.000 exemplares e um impacto considerável na opinião pública portuguesa. Ao mesmo tempo, a Comissão de Justiça e Paz do Porto também se pronunciou de forma explícita sobre o colonialismo português, ao passo que o padre Mário de Oliveira foi preso, depois da sua homilia, em 21 de março de 1973. Para o padre João Maria Van Hurki, de nacionalidade holandesa, o destino foi diferente: ele foi expulso do país por causa de um sermão que pronunciou no dia da paz (ALMEIDA, 2004). 
O episódio da capela do Rato assinalou uma enésima fratura entre Governo de Marcelo Caetano e larga parte do catolicismo democrático. Ainda segundo conta Maria Conceição Mota, a vigília da passagem do ano de 1972 para 1973 foi preparada com todos os cuidados possíveis.

A capela do Rato foi escolhida, segundo conta a testemunha, devido à sua tradição de um lugar pequeno, mas em que a mensagem evangélica era vivida intensamente e largamente difundida para fora dos círculos católicos. Esta opção também foi feita por causa das homilias do padre Alberto Neto, sempre muito críticas, mas não tão descobertas de permitir uma ação contra a ele por parte da PIDE.

Na Igreja do Rato, a missa vespertina do dia 30 de dezembro de 1972 foi celebrada por dom João Seabra Dinis, e foi a própria Maria Conceição Mota a pegar o microfone, anunciando a vontade de passar dois dias dentro da capela, de jejum e em greve de fome, para demonstrar solidariedade para com as vítimas da guerra colonial e contra o posicionamento ambíguo da hierarquia católica.

Até o fim do seu Governo, Caetano e a polícia política não deixaram de perseguir os católicos que estavam desafiando a opção colonial da guerra na Guiné-Bissau, em Moçambique e na Angola. Figuras de destaque do catolicismo moçambicano, por exemplo, foram expulsas e presas uma vez chegadas em Lisboa, como é o caso de dom Manuel Vieira Pinto, bispo de Nampula, mas oriundo do São Pedro de Aboim, expulso em março de 1974, nas vésperas da revolução dos cravos, acusado de apoiar a luta de libertação.

\section{Os Combonianos diante do colonialismo português através do jornal Nigrízia}

"Nigrizia" é um termo criado pelo fundador da ordem dos missionários Combonianos (1867) e das Irmãs Missionárias Pias Mães da Nigrizia (1872), o italiano Daniele Comboni (1831-1881). Comboni, canonizado em 2003 pelo Papa João Paulo II devido à sua obra em África e ao que a Igreja Católica considera de milagre (a cura da jovem sudanesa Kubna Abdel Aziz). 
Depois da ordenação episcopal, Comboni foi Bispo de Claudiópolis de Isauria e Vigário apostólico da África Central em 1877. A obra de toda a sua vida tem-se concentrado na evangelização e resgate dos africanos, com o lema, "salvar a África com os África" - patente na sua obra principal, o Plano pela Regeneração da África - apresentado ao longo do Concílio Vaticano I, com o apoio do Papa Pio IX e do Cardeal Barnabò, e fortemente apoiado em 1871 pela poderosa Sociedade de Colónia (NHAUELEQUE; BUSSOTTI, 2019).

Comboni, apesar de ter uma imagem bastante estereotipada dos Africanos, segundo o espírito dos tempos em que viveu, deve ser considerado como um revolucionário dentro da Igreja Católica e ainda mais no que diz respeito ao sentido e à estratégia da missionação em África (ROMANATO, 2017).

O termo Nigrizia que ele utilizou - e que era bastante comum no século XIX, indicando o país dos pretos, nomeadamente o Sudão - nunca foi exatamente definido, confundindo-se com outras palavras sinónimas usadas pelo missionário, tais como "África", "Etiópia" e similares. Neste conceito Comboni recolhia todos os elementos típicos da civilização africana, e foi este mesmo conceito que foi escolhido quando chegou à altura de fundar a revista que, até hoje, continua as suas publicações a partir da sede central dos Combonianos, localizada em Verona, Norte da Itália.

A revista Nigrizia foi fundada, com essa denominação, em 1883, substituindo os "Annali" da Associação do Bom Pastor, que tinham visto a luz em 1872, focados na difusão do pensamento e da obra de Comboni. Em 1885 passou a fazer suas publicações mensalmente, e, até hoje, ela continua com esta periodicidade, tendo sido complementada, nos últimos anos, pela versão diária online, nigrizia.it (CHI SIAMO, c2021).

A viragem atual da revista Nigrizia deu-se em 1958, quando, a uma abordagem focada na obra de missionação dos Combonianos, o então diretor, Enrico Bartolucci, transformou o periódico numa ferramenta de conhecimento geral de toda a realidade africana. Entretanto, no período que aqui mais interessa, ou seja, nos anos que antecedem as independências das colónias africanas lusófonas, o diretor Renato Sesana assume um posicionamento claro e explícito com relação a tal assunto. Aliás, será justamente a libertação e a luta pela 
independência desses territórios a constituir o tema chave desta época e desta direção, que se prolongará até 1978, quando Alex Zanotelli assumirá a responsabilidade do periódico (CHI SIAMO, c2021).

O material selecionado conta com 13 textos julgados relevantes para os efeitos desta pesquisa, publicados entre 1971 e 1975, dos quais uma larga prevalência (sete) foram escritos diretamente pela redação do periódico, e os outros por parte de padres geralmente combonianos e de outras ordens. Tais textos refletem o ponto de vista da redação de Nigrizia em relação a uma série de assuntos que foram já abordados nos pontos anteriores, do ponto de vista do debate interno a Portugal, e que podem ser resumidos como se segue:

1. Posicionamento com relação a Portugal e às lutas de libertação dos países lusófonos africanos;

2. Posicionamento com relação à Igreja Católica de Roma, de Portugal e dos territórios ultramarinos, com destaque especial para Moçambique;

3. Posicionamento com relação à atividade de missionação, presente e futura;

4. Posicionamento com relação ao novo Estado moçambicano independente e nomeadamente ao partido hegemônico, a FRELIMO.

\subsection{Posicionamento com relação a Portugal e às lutas de libertação dos países lusófonos africanos \\ O posicionamento que a revista Nigrizia expressa com relação à política} colonial portuguesa e às lutas de libertação dos territórios ultramarinos não deixa espaço a muitas dúvidas. Tal posicionamento é baseado na análise das decisões políticas assumidas pelo Governo-Caetano em volta da complexa matéria colonial que, como visto acima, sobretudo na década de 1970 iniciou a ter uma oposição firme dos católicos progressistas portugueses.

O primeiro aspeto que o periódico critica no início de 1971, tem a ver com a cosmética reforma de Caetano em volta dos territórios coloniais em 1971. Com efeito, Caetano tinha apostado muito - no seio da reforma constitucional - a respeito das mudanças sobre o Ultramar; aliás, ele próprio afirmou que a parte 
mais significativa das alterações constitucionais tinham a ver com a matéria colonial, e foi por isso que foi ele, pessoalmente, a redigir tais modificações, propondo-as ao Parlamento, em dezembro de 1970 (SILVA, 2019).

Nesta senda, no fim de um longo e complicado debate parlamentar, o pacote legislativo de revisão constitucional de Caetano foi aprovado mediante a L. 3/71, com poucas alterações significativas em relação à proposta inicial do Governo. Assim sendo, o Estado continuou a ser unitário, mas "regional", com autonomia regional exclusiva para as províncias ultramarinas, cujos estatutos só podiam ser aprovados por parte da Assembleia Nacional.

Em suma, fora da parte meramente formal, pouco tinha mudado na vida efetiva dos territórios coloniais, daqui o ceticismo expresso pela revista Nigrizia, inclusivamente citando Marcelino dos Santos, a segunda figura mais importante da FRELIMO, depois de Samora Machel, solidarizando com a sua insatisfação (REDAZIONE, 1971a).

Entretanto, o posicionamento mais firme assumido pelos Combonianos italianos através da Nigrizia foi expresso mediante um artigo - ainda de autoria da redação - de 1972, abertamente crítico em relação à política colonial portuguesa. A análise inicia de longe, ou seja, de 1960, quando Mário de Andrade, histórico, líder e intelectual do MPLA e que depois se empenhou no fortalecimento do movimento da negritude em Paris, juntamente com outros membros influentes daquele partido, escreveu um documento ao Governo de Lisboa para convidar Caetano a reconhecer a independência de Angola.

A reação não foi só negativa, mas - em jeito de retaliação - o irmão do Mário de Andrade, o sacerdote Pinto de Andrade, foi preso em Luanda (REDAZIONE, 1972). Diante dum apelo de foragidos britânicos e caboverdianos no sentido de reconhecer a independência de Angola, o Governo de Lisboa ignora tal proposta, suscitando uma veemente polémica da revista: "Ignorar o adversário. Esta é a política que até hoje continua” (REDAZIONE, 1972, p. 4).

Em paralelo, o artigo traz elementos de esperança: os adormecidos povos da África lusófona finalmente se despertaram, e a guerrilha de FRELIMO, MPLA e PAIGC obriga o exército português a lutar em três frentes, com 200.000 soldados, 
e gastando 43\% do orçamento do Estado para esta guerra. A crítica da Nigrizia se estende também para os países vizinhos de Moçambique, nomeadamente África do Sul e então Rodésia do Sul, hoje Zimbabwe, que - além de serem regimes racistas - ajudavam Portugal com armas e dinheiro.

Nesta linha de duras críticas, a Nigrizia se direciona sobretudo à NATO que constitui o alvo principal das denúncias do periódico, uma vez que esta organização (Estados Unidos acima de tudo) troca a manutenção das suas bases militares nos Açores com o fornecimento de armas para a luta colonial ao exército português. E finalmente, a questão se estende também aos "interesses do mundo capitalista" no sentido geral, como demonstram os grandes interesses na construção e exploração da hidroelétrica de Cahora Bassa, na província moçambicana de Tete (REDAZIONE, 1972, p. 6).

Portanto, os mesmos conceitos e as mesmas acusações são lançadas pela Nigrizia contra o Governo português e contra a NATO num artigo de 1973, que é complementado por uma amostra fotográfica de atos brutais perpetrados por parte da tropa portuguesa em Moçambique, com objetivo de despertar o interesse da comunidade internacional diante de um conflito que estava sendo obscurecido por outros, aparentemente mais trágicos e politicamente atraentes, tais como no Vietname, no Biafra e no Burundi (REDAZIONE, 1973a).

O distanciamento do Governo português e dos seus aliados se acentua com o aproximar-se da independência, em paralelo a gestos cada vez mais violentos do Governo de Lisboa, por exemplo aquando da expulsão do território moçambicano de 11 missionários, com uso da violência sobre o dehoniano Domenico Liuzzi, e a expulsão de dom Manuel Vieira Pinto, bispo de Nampula, capturado logo depois da sua chegada no aeroporto de Lisboa (MILAN, 1974).

\subsection{Posicionamento com relação à Igreja Católica de Roma, de Portugal e} dos territórios ultramarinos, com destaque especial para Moçambique

As críticas políticas acima sinalizadas, que levaram a Nigrizia a um apoio explícito dos movimentos de libertação das colónias africanas portuguesas, trazem, como sua consequência direta, um posicionamento diante de quem tais 
lutas contrastam. A referência é, essencialmente, à Igreja Católica oficial e às suas altas hierarquias.

Viu-se acima quantas críticas a Igreja portuguesa recebia dos católicos progressistas. O Nigrizia amplifica tais críticas, alastrando-as, em parte, à própria Igreja de Roma, que em Portugal não tinha sido alvo de nenhuma polémica, aliás, representara o ponto de luz a que se agarrar para desencadear a luta no seio da conservadora Igreja lusitana.

Segundo o ponto de vista dos Combonianos, a própria Igreja de Roma podia ser mais decidida e menos ambígua com relação à questão colonial: se é verdade - admite o jornal - que em muitas declarações a Igreja tem demonstrado de que lado estar, também se assinala que não existe um documento em que a Santa Sé proclame o direito desses povos à independência.

E, a propósito disso, a Nigrizia define de "profético" o encontro concedido pelo Papa aos três líderes de FRELIMO, MPLA e PAIGC no Vaticano em 1970, mas ao mesmo tempo não perdendo a ocasião de criticar a diplomacia vaticana e o diário da própria Santa Sé, “L’Osservaotre Romano”, que - como visto acima tinham procurado diminuir a importância de tal encontro para não irritar o Governo português, acalmando a opinião pública católica conservadora (REDAZIONE, 1972).

Ainda no mesmo artigo, retomando o assunto da retirada dos Padres Brancos de Moçambique, a Nigrizia cita o superior regional desta congregação em Moçambique, padre Bertulli, que tinha solicitado à Igreja no sentido de se pronunciar explicitamente sobre a questão colonial portuguesa, chamando a atenção de que a Igreja deve fugir da tentação de se apoiar no poder terreno, contando apenas na força de Deus.

Se a crítica à Igreja de Roma é atenuada graças ao posicionamento do Papa, que é aqui contraposto à alta hierarquia vaticana, muito mais pesadas são as observações polémicas no que diz respeito à Igreja de Moçambique. Aqui também a Nigrizia faz distinções entre a maioria da hierarquia do clero local e algumas figuras, tais como o supramencionado bispo de Nampula, Dom Manuel 
ou a larga maioria dos missionários, que se engajaram corajosamente no apoio aos movimentos de libertação.

Entretanto, as críticas são muito mais abertas e circunstanciadas, chegando a falar de uma verdadeira crise da Igreja moçambicana, representada como sendo em estado de acusação (REDAZIONE, 1971b).

Tal posicionamento deriva da postura de cumplicidade - segundo os Combonianos - que a Igreja de Moçambique teve diante da questão colonial com o Governo português, em associação com a parte mais reacionária do catolicismo naquele território colonial, que teria contribuído a denigrir a imagem dos missionários e a expulsar o Vigário Geral da Diocese da Beira, mons. Duarte de Almeida, assim como o padre da Consolata, Celio Regoli, com a aprovação do arcebispo de Lourenço Marques, mons. Alvim Pereira.

Diante deste cenário, os Combonianos vão ainda mais longe: segundo a Nigrizia, a confusão entre Estado e Igreja, em Moçambique, é total, e quem combate em favor da justiça social é julgado de subversivo e marginalizado. 0 silêncio da hierarquia católica local soa como sendo incompreensível, definindoa como "amordaçada” (REDAZIONE, 1971c, p. 34). Uma postura esta, não aceitável, em consideração das tantas chacinas, torturas e violências perpetradas pela tropa portuguesa contra os civis indefesos (REDAZIONE, 1973b).

\subsection{Posicionamento com relação à atividade de missionação, presente e futura}

Todas as críticas contra o Governo português, a Igreja de Roma e sobretudo de Lourenço Marques (hoje Maputo) levam a Nigrizia a desenvolver o assunto a que mais os Combonianos estão interessados, a reforma da missionação. É neste capítulo que a influência do fundador desta ordem religiosa, Daniele Comboni, se faz sentir com maior intensidade: assim como ele foi na sua época revolucionário diante do imobilismo da Igreja em relação à questão africana, assim os seus seguidores procuram voltas às origens, propondo uma missionação diferente, coerente aos ideais evangélicos que Comboni - segundo eles - sempre priorizou. 
"Os missionários já não aceitam de serem passivos executores de ordens. Eles querem assumirem uma responsabilidade ativa na edificação da Igreja [...]. A época do paternalismo e do autoritarismo já acabou" (REDAZIONE, 1972, p. 8). E acrescentam: "E os missionários resolveram falar. E cumprem gestos proféticos, surpreendentes pela sua novidade" (REDAZIONE, 1972, p. 8). Tais reflexões representam a conclusão de um percurso de análise coletiva por parte dos Combonianos que deve desaguar num diferente tipo de missionação em África, tendo como base o Concílio Vaticano II, reclamando um peso diferente dentro da Igreja oficial.

As conclusões supra delineadas derivam de dois fatores essenciais, ligados à dura experiências nas terras africanas de língua portuguesa: por um lado, os massacres desumanos das tropas coloniais, e por outro a reação do Governo português em resposta à nova postura da maioria dos missionários combonianos e de outras ordens e congregações, que denunciam tais atos, almejando um mundo mais livre e justo.

Na primeira parte deste estudo já se apresentou o impacto que os massacres como o de Wiryiamu, na província de Tete, teve na opinião pública portuguesa. No contexto em que a Nigrizia era publicado, ou seja, na Itália dos anos 70, abalada em âmbito religioso pelo Concílio Vaticano II, e político-cultural pelo surgimento de movimentos que pautavam por novos direitos (de tipo sexual, ambiental, ético, procurando pacificar o mundo fora das tensões da guerra fria), o efeito de detonação das notícias que provinham dos missionários, era ainda maior.

Eram justamente os missionários que, cansados do papel de neutralidade política da Igreja, iniciaram a denunciar e propagar as atrocidades dos portugueses em Moçambique e nas outras colónias em conflito. E a Nigrizia não perde a oportunidade para destacar este papel essencial, de regeneração de todo povo e de toda a Igreja exercido pelos missionários em terras moçambicanas.

Em paralelo, a onda de violências e expulsões desencadeadas pelo Governo português contra missionários e religiosos engajados, representa o outro elemento que provoca uma radicalização do posicionamento dos Combonianos com relação à questão colonial e à tarefa libertadora da missionação. Mesmo 
quando a moderada Conferência Episcopal de Moçambique - liderada pelo bispo de Quelimane, mons. Nunes Francisco Texeira - resolve escrever uma carta ao governador, depois do massacre de Wiryiamu, a resposta que é recebida procura minimizar o fato, garantindo ter sido aberto um inquérito para averiguar a verdade, mas também realçando que, lá onde elementos terroristas atuam, fica difícil prevenir episódios similares, entretanto praticados por parte de "forças isoladas" (REDAZIONE, 1973c, p. 35).

A este propósito, os Combonianos da Nigrizia assumem uma postura de respeito quer para aquelas congregações que decidem sair de Moçambique, quer para os que vão permanecer ao lado das populações. Tal postura se deve à necessidade de querer mostrar, sobretudo à Igreja oficial, que os missionários são unidos, têm preocupações comuns, embora a decisão contingente pode sofrer alguma diferenciação entre esta e aquela congregação. Todos eles, porém, pretendem participar e até liderar o processo de renovação evangélica da lgreja, a partir das dificuldades encontradas nas terras africanas.

Este posicionamento, unívoco, mas diferenciado, é ilustrado por um missionário que teve um papel relevantíssimo na compreensão do pensamento africano do ponto de vista cristão, Adalberto Pavan, melhor conhecido como Adalberto da Postioma, ele também expulso da Angola devido às suas posições de apoio explícito à luta de libertação (PAVAN, 1972).

Pavan recolhe as declarações públicas dos maiores representantes missionários em Moçambique, os quais defendem a ideia de uma missionação negativamente influenciada pelo clima de hostilidade, mas sobretudo de ambiguidade do Estado português e da Igreja de Moçambique com relação às atividades dos missionários.

O superior geral dos Padres Brancos justifica que a sua congregação resolveu deixar temporariamente Moçambique, pois ficar teria significado incarnar um contratestemunho do Evangelho, ao passo que o representante dos padres da Consolata expressava as mesmas preocupações, embora a sua congregação decidiu ficar ao lado das populações. 
Ainda mais explícita é a ideia expressa pelo Padre Provincial e pelo Padre Superior dos Capuchinos de Trento, missionários em Moçambique, que referem que o posicionamento de neutralidade da Igreja moçambicana coloca sérios problemas de objeção de consciência nos missionários daquela congregação, reparando na absurdidade desta postura, abandonando a população civil às piores violências do exército português. A tais vozes que assinalam grande preocupação e embaraço ético se contrapõe, idealmente, mons. Pereira, que declara que governar Moçambique é uma tarefa da "velha Europa", uma vez que os africanos são incapazes de qualquer forma de autogovernação (PAVAN, 1972, p. 36). Fechando, assim, qualquer possibilidade de diálogo com os missionários e com o povo moçambicano.

\subsection{Posicionamento com relação ao novo Estado moçambicano independente e nomeadamente ao partido hegemônico, a FRELIMO}

Nos meses entre o fim do Governo de transição e o Governo independente, a questão religiosa em Moçambique começou a tomar contornos mais definidos. Com efeito, se é verdade que quase todos os líderes da FRELIMO tinham recebido uma educação religiosa (a maioria de tipo católico, como Chissano ou o próprio Samora Machel, outros de tipo protestante, como Mondlane), também é verdade que a política religiosa não favoreceu a liberdade de culto (que entretanto nunca foi formalmente retirada), aliás o novo Governo de Samora Machel adotou uma postura conflituosa para com a religião, quer a tradicional, quer as formais, onde principalmente o catolicismo sofreu as consequências piores.

Uma ideia bastante clara daquilo que Machel pensava das religiões pode ser lida num dos seus discursos, pronunciado em 1974, poucos meses antes da proclamação formal da independência. Subdividindo o mundo entre duas classes antagónicas que historicamente lutaram pelo poder, Machel coloca a religião dentro daquela parte do mundo onde atuam os "inimigos do povo" e que, portanto, na melhor das hipóteses, só pode ser tolerada: "No nosso país antes da conquista colonial, os régulos e Chefes tribais que exerciam o poder afirmavam que o seu poder representava a vontade dos antepassados", 
obrigando as massas à obediência às políticas exploratórias do colono. A mesma abordagem é usada ao falar das Igrejas, particularmente da católica.

Com efeito, os colonialistas "difundiram numerosas religiões no nosso seio que, dividindo as massas, enfraqueciam-nas. Ao mesmo tempo as religiões todas elas pregavam ao Povo a resignação". Machel vai ainda mais longe, englobando nessa conspiração contra o povo moçambicano a própria ação dos missionários. Estes "ensinavam-nos que desobedecer ao Governo e ao colono era pecado, que devíamos estar muito gratos ao colonialismo português porque trazia-nos a verdadeira fé" (MACHEL, 1974, p. 5).

Em suma, se o posicionamento da FRELIMO, mesmo antes da independência, estava relativamente claro em relação à questão religiosa, as forças mais progressistas do catolicismo, entre as quais grande parte das congregações missionárias, se iludiram de que podia ser bem aceites no novo estado independente. Tal convicção se baseia na ideia de que Moçambique - a ainda mais a FRELIMO - tinha uma "dívida" com os missionários combonianos, dehonianos, da consolata e dos padres brancos, pois estes sempre assumiram um posicionamento de aberto apoio à luta de libertação, não apenas em Moçambique, mas - como visto acima - mesmo em outros territórios coloniais da África portuguesa, como Angola. Entretanto, a "expectativa" que os missionários podiam ostentar diante da independência de Moçambique não foi reconhecida por parte do socialismo radical de Samora Machel, e a sua obra também foi englobada na geral onda de raiva do povo moçambicano contra as hierarquias católicas que demonstraram, na madre-pátria assim como no Ultramar, todo o seu conservadorismo e miopia política diante do processo de descolonização.

A revista Nigrizia traz, em alguns dos seus artigos escritos entre 1974 e 1975, toda esta tensão ética, política e religiosa, que desagua em incerteza e sobretudo em ilusão de que o novo Governo não podia reconhecer o mérito de missionários que até sacrificaram suas vidas, de várias formas, para apoiar a libertação do país.

O primeiro artigo que aborda a postura do novo Estado diante da religião traz a assinatura do Padre Claudio Crimi, missionário comboniano. Ele tinha sido 
expulso, juntamente com outros missionários, pelo Governo português pouco antes da independência. Em dezembro de 1974, ainda com o Governo de transição liderado por Joaquim Chissano, ele volta à Moçambique e escreve um artigo na Nigrizia, onde testemunha sobre o clima que se respirava naquela altura, no país: "Liberdade é a palavra que a gente hoje respira [...]. Entretanto, as forças da reação não foram eliminadas" (CRIMI, 1974, p. 19). As páginas que a revista dedica ao retorno do padre a Moçambique trazem também mais duas partes: o testemunho de Roberto Fernandes, um jovem da FRELIMO que lutou contra os Portugueses, e que foi capturado e torturado.

Fernandes escreveu uma carta aos familiares, que a Nigrizia publica na íntegra, confirmando a condenação sem apelo de um regime que os Combonianos constantemente denunciaram como desumano e fora do tempo. E, mais abaixo, o jornal traz uma entrevista a Padre Filipe Couto, um padre de origem portuguesa da congregação da Consolata, que se tinha juntado à FRELIMO, tornando-se um dos conselheiros de Samora Machel. Depois da independência, Padre Couto tornou-se um dos personagens de destaque da educação em Moçambique, assumindo primeiro o papel de Reitor da Universidade Católica de Moçambique, na Beira, e depois da Universidade Eduardo Mondlane, em Maputo. Na entrevista à Nigrizia, Padre Couto apresenta um quadro relativamente realístico - embora com uma certa veia de otimismo - de como a FRELIMO irá lidar com a Igreja católica e seus missionários. E as suas palavras influenciarão consideravelmente a postura geral dos Combonianos e dos outros missionários em relação ao Governo independente de Moçambique.

Couto classificará a FRELIMO como aquela que não pautaria pelas vinganças contra os brancos, mas que este perigo poderá estar presente em iniciativas individuais. Couto garante que a FRELIMO sempre manteve uma postura de "neutralidade para com as religiões". Até hoje - recorda padre Couto - a FRELIMO ficou atenta para que as religiões não constituíssem "motivo de divisão" (S.C, 1974, p. 22). E, ele diz, continuará a fazer isso, não tolerando nenhum conflito inter-religioso dentro do território nacional, assim como "irá combater todas as ideias de fatalismo, de medo do sagrado, patentes sobretudo na religião animista” (S.C., 1974, p. 22). 
Padre Couto passa a analisar aquilo que o Governo espera de cada confissão religiosa: os muçulmanos, segundo ele, serão chamados a sair do seu tradicional fechamento, para interagir de forma mais aberta com o resto do país e da sociedade; os protestantes, que o missionário da Consolata reconhece ter pago preços muito elevados por estarem, na maioria dos casos, ao lado dos libertadores, terão de demonstrar que não são agentes do capitalismo financeiro suíço e americano; e finalmente a Igreja Católica, "ligada estreitamente às vicissitudes portuguesas, é a que se encontra na situação mais delicada" (S.C., 1974, p. 22).

Acima de tudo, o novo regime procederá a uma subdivisão nítida entre Estado e Igreja, diferentemente daquilo que acontecia com Portugal. Mas segundo padre Couto - tal circunstância irá aliviar de um fardo muito pesado a própria Igreja, que poderá se dedicar exclusivamente à cura das almas. Tal mudança, porém, sublinha o padre, terá de envolver sobretudo os bispos moçambicanos, aos quais Couto lança mais de uma chamada de atenção: "Os Bispos de Moçambique deveriam repensar seriamente ao seu posicionamento, ao que fizeram e ao que não fizeram em defesa dos direitos do seu povo", concluindo com um apelo que deixa pouco espaço a interpretações, e que serve, provavelmente, para ajudar a Igreja Católica moçambicana, no seu todo, a livrarse da imagem de cúmplice do regime colonialista, com o objetivo de ser aceite por parte do novo regime da FRELIMO, ou, pelo menos, de evitar novas perseguições: "Se alguém entre eles se aperceber de ter colaborado demais com o governo português, deveria pedir ao Papa para ser substituído" (S.C., 1974, p. 22). A conclusão também é clara, deixando, porém, transparecer um certo otimismo, quanto ao possível espaço das congregações missionárias na nova nação: "Chegou o momento de recomeçar com maior compromisso a anunciar o Evangelho", numa união muito sólida entre missionários e indígenas (S.C., 1974, p. 22). Finalmente, o outro risco possível que Couto entrevê tem a ver com a possível "frelimização" da Igreja: o que representaria, segundo ele, um passo pela frente, mas seria na mesma "um grande erro" (S.C., 1974, p. 22).

A entrevista com o padre Couto deixa em aberto questões delicadas que a Igreja de Roma terá de enfrentar, como a sua excessiva proximidade ao regime 
colonial português, sobretudo nos últimos anos, e o papel nada progressista dos seus bispos, ou da maioria deles.

Entretanto, Couto procura distinguir entre esta Igreja e a Igreja dos missionários, induzindo os Combonianos da Nigrizia a uma leitura provavelmente demasiado otimista em relação a uma situação que, naqueles meses, foi delineando-se como extremamente crítica para todas as componentes da Igreja Católica.

Tal posicionamento se manifesta na sua forma mais clara num artigo ainda de autoria do Padre Crimi. Neste texto, escrito logo depois da independência formal de Moçambique, o autor, depois de ter descrito uma situação de violência difusa e com fortes bases históricas, de que os brancos teriam a maior responsabilidade, Crimi passa a analisar a política da FRELIMO, elogiando-a, no sentido de levar a cabo um "grande esforço de sensibilização social e de pacificação, sobretudo nas cidades”, em que, graças à organização de comité locais, " o povo [...] acabou tendo nas suas mãos uma boa fatia de poder [...] todo o povo participa e decide" (CRIMI, 1975, p. 16-17).

Crimi vê na "popularização" do poder um dos elementos de maior proximidade entre as políticas sociais da FRELIMO e os ideais evangélicos do Concílio Vaticano II e dos próprios Combonianos, concluindo com uma frase com "sabor" de apologismo, e mostrando que aquele risco de "frelimização" da Igreja de que padre Couto tinha falado poderia verificar-se efetivamente: "Boa parte do programa da FRELIMO, a nível social, é Evangelho puro" (CRIMI, 1975, p. 17). Toda a Igreja, conclui o autor, é que deve mudar, esquecendo as cumplicidades do passado.

Finalmente, a dita propensão é também evidente nas palavras do primeiro bispo moçambicano da Igreja Católica, mons. Alexandre José Maria, ordenado juntamente com o bispo do então Porto Amélia, atual Pemba, mons. Januário Machase Nhangumbe. Mons. Alexandre representa, até hoje, a figura de maior destaque da Igreja Católica no Sul de Moçambique, com um posicionamento político historicamente próximo à FRELIMO, e nomeadamente ao seu antigo Presidente, sucessor de Samora Machel, Joaquim Chissano. 
Nesta senda, dom Alexandre define os militantes da FRELIMO como "heróis que em dez anos de lutas têm levado Moçambique à liberdade [...] heróis da floresta, homens corajosos", oferecendo uma sincera colaboração da Igreja ao novo Governo (LA CHIESA..., 1975, p. 25). O comentário do autor da entrevista a mons. Alexandre, Arnaldo Baritussio, não pode deixar de observar que a homenagem do novo bispo moçambicano aos heróis frelimistas "fugiam à suspeita de oportunismo" (BARITUSSIO, 1975, p. 22). Entretanto, tal perigo poderá ser superado, segundo o autor, associando-se ao apelo de mons. Alexandre, em que o prelado incita toda a Igreja a passar dos privilégios gozados durante o regime português a um renovado e mais evangélico espírito de serviço para com um povo que ainda traz muitos sinais de sofrimento, violência e pobreza que o regime de Samora Machel procurará ultrapassar.

É com esta análise, que evidencia uma mistura de esperança, consciência de cumplicidades excessivas da Igreja com o passado colonial, apreciação das políticas "populares" do novo Governo que coincidem, em larga medida, com os anseios dos Combonianos e de muitos outros missionários, que a Nigrizia se prepara a enfrentar uma nova estação de dificuldades e, em parte, intolerâncias, desta vez provenientes do lado contrário do colono, a FRELIMO. E foi justamente a constante oscilação entre tolerância, perseguição e resistência, muitas vezes criticando uma Igreja moçambicana que, sobretudo no Sul, se aproximou demais à FRELIMO, que os Combonianos em Moçambique tiveram de enfrentar, experimentando assim, o espírito mais autêntico do sentido da sua missionação.

\section{Conclusões}

Esta pesquisa quis compreender o complexo panorama do catolicismo nos anos que antecederam a obtenção da independência das antigas colónias africanas de Portugal, com ênfase especial para os missionários combonianos. Seu posicionamento em volta das várias facetas desta parte da história do colonialismo português foi extraído a partir da análise do jornal dos Combonianos italianos, Nigrizia, onde confluíram, naquela época, tendências diversificadas, mas com um elemento em comum: o apoio aos movimentos de libertação nacional 
contra o colonialismo de Lisboa, e a crítica ao conservadorismo da Igreja portuguesa, moçambicana e, em parte menor, romana.

Tal complexa articulação valeu aos missionários mais comprometidos com a causa da libertação - não só combonianos, mas, como visto ao longo deste artigo, dehonianos, da consolata, os padres brancos - expulsões, perseguições, torturas por parte do Estado português. Entretanto, o apoio, direto ou indireto, que eles deram à FRELIMO e, mais em geral, aos movimentos de libertação nos PALOP, não thes valeu o salvo-conduto para que fossem aceites com agrado por parte do novo Governo socialista de Samora Machel, salvo exceções individuais, como a representada por padre Couto.

Com efeito, o Governo da FRELIMO meteu tudo no mesmo bojo, e a péssima fama de que a Igreja Católica e as suas hierarquias gozavam junto aos libertadores acabou engolindo numa postura negativa e, por vezes, persecutória, os próprios missionários combonianos ou todo aquele pessoal clérigo que olhou com horror às políticas de limpeza política que a FRELIMO estava preste a realizar. Uma questão que fica aqui como tal, pois não seria possível responder a ela sem levar a cabo outro tipo de pesquisa, é até que ponto os combonianos da Nigrizia tinham a convição de que o novo governo marxista moçambicano teria assumido uma postura tolerante para com eles, em reconhecimento do seu posicionamento ao longo da luta pela independência, ou se eles, simplesmente, não conseguiram avaliar o sentido político da viragem socialista da FRELIMO, salvo compreenderem pouco tempo depois a natureza deste regime, que não só foi extremamente duro com a igreja católica, mas sobretudo implementou uma série de violações dos direitos humanos fundamentais que mereceram a intervenção repetida do Vaticano, juntamente com organizações internacionais tais como Amnesty International, implorando a cessação de tais barbaridades.

Porém, esta seria uma pesquisa diferente daquela que aqui foi apresentada, que se concluiu, consoante as páginas da Nigrizia que foram analisadas, com a expetativa de que o novo Governo pudesse olhar para os missionários católicos de forma diferente em relação ao clero mais ligado à experiência colonial portuguesa. O que não aconteceu, como se sabe. 


\section{Referências}

ALMEIDA, João Miguel. A oposição católica ao Marcelismo (1968-1974). Lusitánia Sacra, Lisboa, 2a série, n. 16, p. 273-293, 2004. Disponível em:

https://revistas.ucp.pt/index.php/lusitaniasacra/article/view/7075. Acesso em: 12 abr. 2021.

ANTUNES, José Freire. Nixon e Caetano: promessas e abandono. Lisboa: difusão Cultural, 1992.

BARITUSSIO, Arnaldo. Dal privilegio al servizio. Nigrizia, Verona, p. 22-26, giugno 1975.

BARROSO, Luís. Marcelo Caetano e a origem do exercício ALCORA. Cadernos de Estudos Africanos, Lisboa, n. 35, p. 35-59, 2018. Disponível em:

https://journals.openedition.org/cea/2585. Acesso em: 14 fev. 2021.

BRANDÃO, Pedro. Os padres de Macuti. História, Lisboa, n. 67, p. 44-49, 2004.

CABREIRA, Pamela Peres. Percepções coloniais do Salazarismo ao Marcelismo: guerra de libertação em África e a vaga revolucionária na metrópole. Outras Fronteiras, Cuiabá, v. 5, n. 1, p. 63-84, 2018. Disponível em:

http://www.ppghis.com/outrasfronteiras/index.php/outrasfronteiras/article/view /308. Acesso em: 5 jan. 2021.

CHI SIAMO. Nigrizia, Verona, c2021. Disponível em:

https://www.Nigrizia.it/chisiamo. Acesso em: 23 abr.2021.

CRIMI, Claudio. Mozambico diario di un ritorno. Nigrizia, Verona, p. 18-23, dic. 1974.

CRIMI, Claudio. Indipendenza nel segno dell'uomo. Nigrizia, Verona, p. 16-17, luglio/ag. 1975.

DE JONG, Albert. Catholic mission and colonialism. Tangaza Journal of Theology \& Mission, Nairobi, n.1-2, p. 64-115, 2015. Disponível em: https://www.researchgate.net/publication/342923895_Catholic_Mission_and_Co lonialism_14720. Acesso em: 17 mar. 2021.

DHADA, Mustafah. O massacre português de Wiriyamu. Lisboa: Tintadachina, 2016. Disponível em: https://tintadachina.pt/wp-content/uploads/massacreportugu\%C3\%AAs-de-wiriamu.pdf. Acesso em: 19 abr. 2021.

ESTÊVÃO, Nuno. Os meios católicos perante a guerra colonial: Reconfiguurações da questão religiosa em Portugal. Lusitánia Sacra, Lisboa, 2a série, n.12, p. 221265, 2000. Disponível em: 
https://revistas.ucp.pt/index.php/lusitaniasacra/article/view/7426. Acesso em: 11 jan. 2021.

HASTINGS, Adrian. Wiriyamu: my Lai in Mozambique. Londres: Search Press, 1974.

HEIDT, Maria Rapela. Development, nations, and "the signs of the times:" the historical context of populorum progressio. Journal of Moral Theology, Nairobi, v. 6, n. 1, p. 1-20, 2017.

JARDIM, Jorge. Moçambique terra queimada. Lisboa: Intervenção, 1976.

JOÂO XXIII, Papa. Pacem in Terris. Roma: Libreria Editrice Vaticana, 1963.

Disponivel em: https://www.vatican.va/content/john-

xxiii/pt/encyclicals/documents/hf_j-xxiii_enc_11041963_pacem.html. Acesso em:

9 apr. 2021.

LA CHIESA e la Rivoluzione in Mozambico. Nigrizia, Verona, p. 25, giugno 1975.

MACHEL, Samora. Estabelecer o poder popular para servir as massas. In: MACHEL, S. A luta continua. Maputo: [s.n.], 1974. Disponível em:

http://www.fafich.ufmg.br/luarnaut/Machel-

Estabelecer\%200\%20poder\%20popular\%20para\%20servir\%20as\%20massas.pdf. Acesso em: 23 jul. 2020.

MARTINHO, Francisco Carlos. A Revolução dos Cravos e a historiografia portuguesa. Estudos Históricos, Rio de Janeiro, v. 30, n. 61, p. 465-478, 2017. Disponível em: https://www.scielo.br/pdf/eh/v30n61/0103-2186-eh-30-610465.pdf. Acesso em: 3 jul. 2020.

MARTINS, Rui Jorge. Sophia de Mello Breyner: missa na Capela do Rato marca trasladação para o Panteão Nacional. SNP Cultura, Lisboa, 02 jul. 2014.

Disponível em:

https://www.snpcultura.org/sophia_mello_breyner_missa_capela_rato_marca_tr asladacao_panteao.html. Acesso em: 8 abr. 2021.

MILAN, Piero. Testimoni scomodi. Nigrizia,Verona, p. 10-19, giugno 1974.

MORAIS, Tomé Pedro. Os clérigos católicos e a luta de libertação nacional em Moçambique: o caso dos Padres de Macuti-Beira. Cadernos de África contemporânea, São Francisco do Conde, v. 3, n. 6, p. 89-106, 2020. Disponível em: https://www.capoeirahumanidadeseletras.com.br. Acesso em: 4 abr. 2020.

NHAUELEQUE, Laura António; BUSSOTTI, Luca. The Conceptualization of Africa in the Catholic Church. Social Sciences \& Missions, Leiden, v. 32, n. 1/2, p. 148176, 2019. 
OLIVEIRA, Pedro Aires de. A política externa do Marcelismo: a questão africana. In: MARTINS, Fernando (org.). Diplomacia e guerra. Évora: CIDHEUS, 2001. p. 233265.

PAOLO VI, Papa. Populorum progressio. Roma: Libreria Editrice Vaticana, 1967. Disponivel em: https://www.vatican.va/content/paulvi/it/encyclicals/documents/hf_p-vi_enc_26031967_populorum.html. Acesso em: 4 jul. 2020.

PAVAN, Adalberto. Mozambico: autorevoli dichiarazioni. Nigrizia, Verona, p. 3536, giugno 1972.

PR. Memórias do dia da libertação pessaol e do país. Ecclesia, Lisboa, 11 abr. 2014. Disponível em: https://agencia.ecclesia.pt/portal/memorias-do-dia-dalibertacao-pessoal-e-do-pais/. Acesso em: 3 maio 2020.

REDAZIONE. Mozambico: quando finirà? Nigrizia, Verona, p. 37-38, febbr. 1971a.

REDAZIONE. Mozambico: una seria riflessione. Nigrizia, Verona, p. 42-43, nov. $1971 b$.

REDAZIONE. Mozambico: partoni i Padri Bianchi. Nigrizia, Verona, p. 33-34, luglio/ag. 1971c.

REDAZIONE. Mozambico senza pace. Nigrizia, Verona, p. 4-11, apr. 1972.

REDAZIONE. Il volto tragico della guerra. Nigrizia, Verona, p. 10-15, apr. 1973a.

REDAZIONE. Un'omelia per la pace. Nigrizia, Verona, p. 37-38, genn. 1973b.

REDAZIONE. I vescovi hanno parlato. Nigrizia, Verona, p. 34-35, dic. 1973c

ROMANATO, G. L'Africa e la missione ai tempi di Comboni. Roma: Università Urbaniana, 2017. Disponível em:

http://www.secolaricomboniane.it/images/allegati/Africa-e-la- missione-Combo ni(1).pdf. Acesso em: 3 jan. 2020.

SALVINI, Gianpaolo. La Chiesa nell'Africa Portoghese. Aggiornamenti Sociali, Milano, n. 963, p. 183-192, 1975. Disponível em:

https://www.aggiornamentisociali.it/articoli/la-chiesa-nell-africa-portoghese/. Acesso em: 9 fev. 2020.

S.C. Frelimo e Chiesa: rapporto delicato. Nigrizia, Verona, p. 22, dez. 1974. 
SCHNEIDMAN, Witney. Confronto em África: Washington e a queda do Império colonial português. Lisboa: Tribuna da História, 2005.

SECCO, Lincoln. A Revolução dos Cravos. Projeto História, São Paulo, n. 47, p. 365-376, 2013. Disponível em:

https://webcache.googleusercontent.com/search?q=cache:_LQOQsClZzAJ:https: //revistas.pucsp.br/revph/article/download/17138/14211+\&cd=10\&hl=ptBR\&ct=clnk\&gl=br\&client=opera. Acesso em: 4 fev. 2020.

SILVA, António. O Império e a constituição colonial portuguesa. Lisboa: Imprensa de História Contemporânea, 2019. Disponível em: https://library.oapen.org/bitstream/handle/20.500.12657/23439/SilvaAD_book.pd f? sequence=1. Acesso em: 4 fev. 2020. 